\title{
Research of damping influence for the transmission of energy in multi-masses systems
}

\section{Jan Warczek}

Faculty of Transport, Silesian University of Technology, Krasińskiego Street 8, 40-019 Katowice, Poland E-mail: jan.warczek@polsl.pl

Received 6 September 2018; accepted 18 September 2018 DOI https://doi.org/10.21595/vp.2018.20228

Check for updates

Copyright $(\underset{C}{ } 2018$ Jan Warczek. This is an open access article distributed under the Creative Commons Attribution License, which permits unrestricted use, distribution, and reproduction in any medium, provided the original work is properly cited.

Abstract. The aim of the research is to determine the impact of damping on the manner of transferring the energy of vibrations from the vehicle's road wheel on the truck body. The work presents the results of simulation tests and real object. The proposed method is an effective tool for the analysis of energy transfer in mechanical systems containing flexible elements (elastic and damping).

Keywords: energy of vibrations, damping of vibrations, truck suspensions.

\section{Introduction}

The moving vehicle is subjected to constant vibration extortions. Due to the need to limit the negative impact of vibration energy on the structural elements of the vehicle as well as people in the vehicle and the load being carried, solutions are used to mitigate this phenomenon. In automotive vehicles there are always two teams responsible for minimizing the impact of vibrations [1]. The first are pneumatic wheels, respectively, which is the first type of mechanical filter reducing extortion from road unevenness.

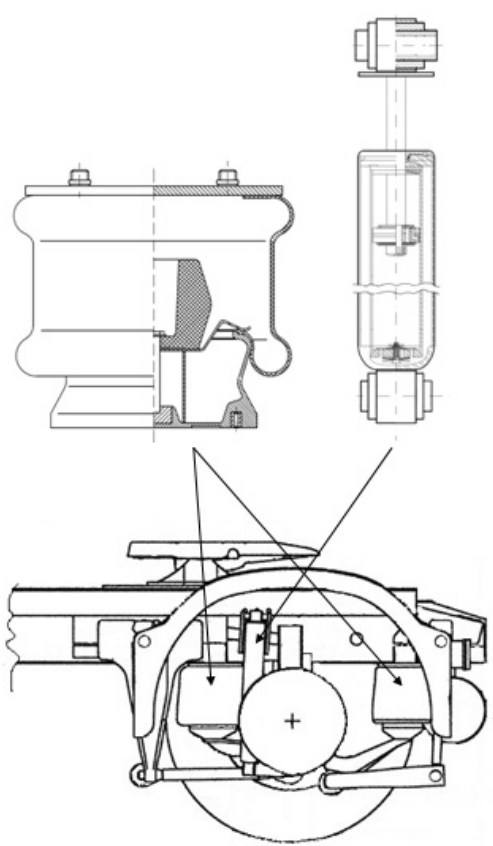

Fig. 1. The flexible elements used in the test vehicle utility

The second is the suspension system, which allows the wheel to be moved relative to the protected bodywork body. In other words, flexible elements that function as vibration damping are commonly used in automotive vehicles. Such a solution, however, always leads to the 
formation of a multi-mass system, which is characterized by specific frequencies of its own vibrations. In commercial vehicle suspensions, pneumatic springs are commonly used, which transfer static and variable loads resulting from operating conditions $[2,3]$. The role of damping elements is played by hydraulic shock absorbers whose basic function is to reduce the speed in the vibrating motion. An exemplary suspension system, which is the subject of research, is shown in Figure 1.

\section{Description of the research problem}

Generally, in mechanical systems requiring the use of shock absorbing cushions, there is no need to use vibration dampers. If the system works in the field of sub-or super-resonance forces, the vibration damping function is fully implemented before elastic suspension. In automotive vehicles, the use of vibration damping elements is necessary due to the operation of these systems in a wide range of extortion frequencies. On the one hand, this is due to external extortions, for example, road unevenness. On the other hand, the vibrations of the vehicle are also influenced by internal constraints, which may include, for example, the unbalance of the road wheels. In both cases, the frequency of vibration extortions depends on the current vehicle speed. The range of vibration extortion frequencies is wide and very often overlaps with the natural frequency of the system. For this reason, in order to limit the amplitudes of vibrations in the automotive vehicles, the elements responsible for damping vibrations are used. The purpose of the conducted research is to determine the effect of the damping type on the manner of transferring the energy of vibrations from the vehicle's road wheel on the vehicle body $[1,4]$.

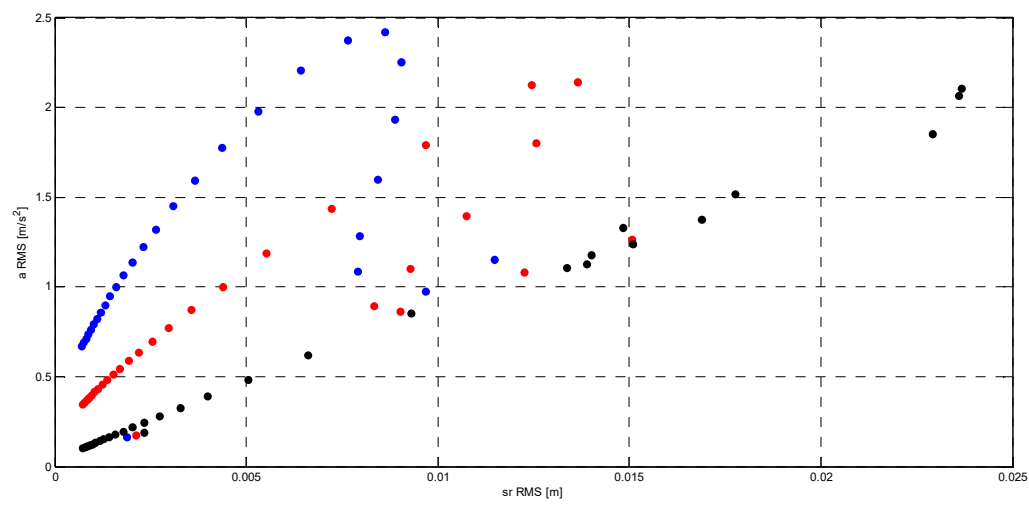

Fig. 2. Changing the damping characteristic for Chirp type extortion from 0 to $30 \mathrm{~Hz}$-amplitude $10 \mathrm{~mm}$. Black colour is $10 \%$ of the nominal attenuation characteristics, respectively: red $-40 \%$, blue $-80 \%$

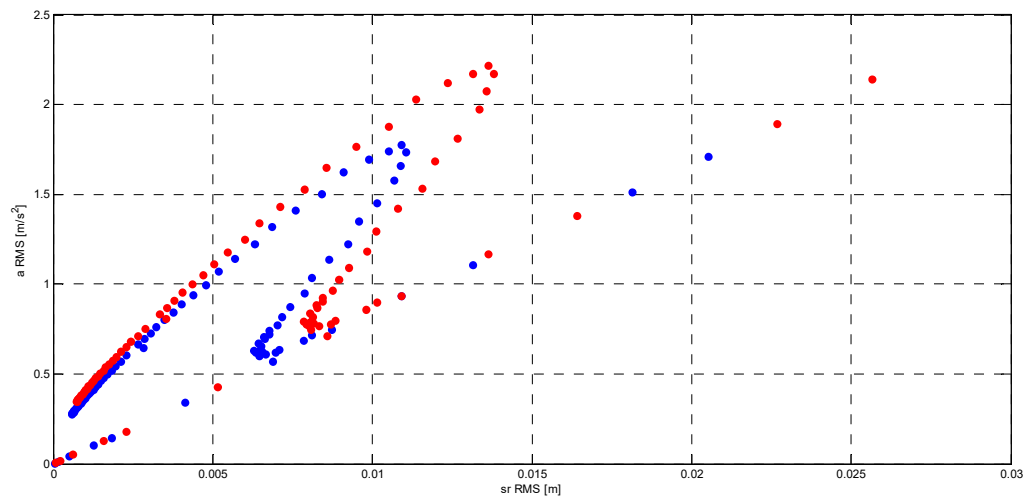

Fig. 3. Results obtained for the Chirp extortion from 0 to $30 \mathrm{~Hz}$ - blue colour amplitude $6 \mathrm{~mm}$, red colour amplitude $10 \mathrm{~mm}$ 
Studies on the impact of damping on the transmission of vibration energy are carried out on a simulation model. In the narrowest range, the vehicle can be simplified to a two-mass dynamic model (2DOF). This type of model is used in research. All parameters of the simulation model are selected based on the tests of the real object, which is a Volvo tractor unit. Due to the adopted scope of extortion, this type of model is used in research assumed that the damping characteristics used in the model will be linear, but different for the compression and stretching movements. The tests used different damping characteristics (the change of attenuation This type of model is used in research designed as a defined percentage of the nominal characteristic) and various types of kinematic extortions. The vibration energy used for the analysis of the studied phenomenon is the RMS values of selected physical quantities describing the vibrations of the object. To assess the energy transmission of vibrations on the body, the relationship between the values: vibration acceleration of the car body and relative displacements of the wheel relative to the car body are used. Simulation research is carried out using deterministic and random extortions corresponding to the real power density functions of road unevenness. Figures 2 and 3 present the results of the relation between accelerations of the body and suspension deflections during sinusoidal extortion with a linearly increasing frequency. Figure 2 shows the results of tests on the model with different damping characteristics. Figure 3 presents the results obtained for various amplitude values of vibration extortions.

The graphs clearly show two areas related to resonance frequencies of the body and suspension. The increase in the value of the amplitude of the force influences proportionally on the form of the relationship between the selected vibration parameters. The increase of damping (Figure 2) affects the increase of the energy of vibrations of the body mass of the vehicle while reducing the displacement of the wheel relative to the body. The presented dependence does not have the form of a function (data of effective values of vibration acceleration fertilizer may occur for various effective values of relative displacements of sprung and unsprang masses), but describes the energy relations between the analysed vibration signals. Figure 4 presents the results of simulation tests obtained for various damping characteristics in suspension induced by stochastic enforcement consistent with the statistical description of road unevenness.

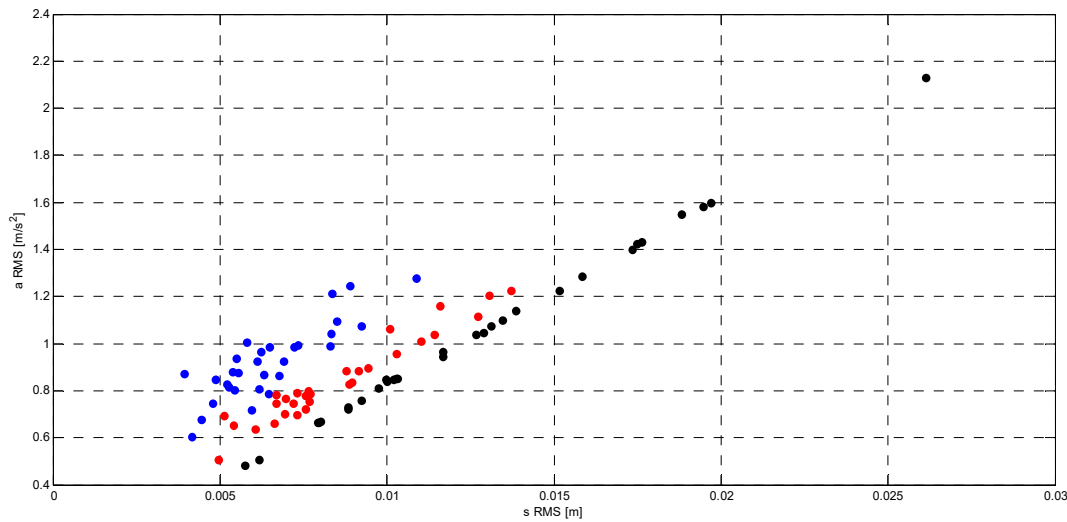

Fig. 4. Results obtained for random exclusion. Black colour is $10 \%$ of the nominal attenuation characteristics, respectively: red $-40 \%$, blue $-80 \%$

In the case of the analysed random force, depending on the attenuation characteristics, there is also a clear differentiation of energy relationships between selected vibration signals. The proposed method allows, on the one hand, the analysis of vibration energy transmission occurring in a multi-mass system. On the other hand, it is also an efficient tool for analysing damping changes in the system. Empirical verification of the developed method is carried out on the real object. Tests are carried out on a Volvo tractor unit. The mounting locations for the measuring sensors are shown in Figure 5. The vibration signals are recorded at a frequency of $25 \mathrm{kHz}$. 


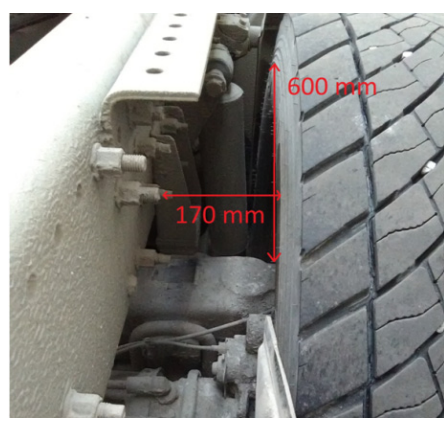

a)

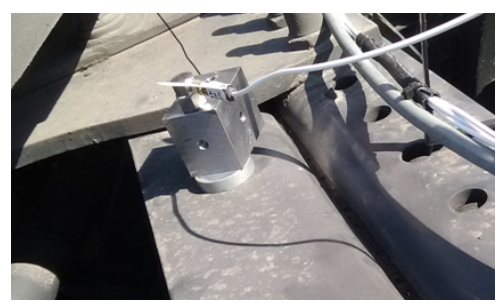

b)

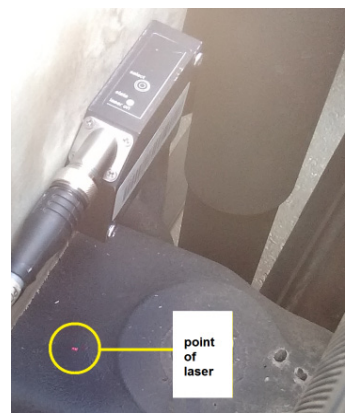

c)

Fig. 5. The view of the place of measurement, the method of fixing the sensors, b) the acceleration sensor of the body, c) the laser sensor of the displacement of the wheel relative to the body

Figure 6 presents the test results obtained for two shock absorbers. The results for the used shock absorber (lack of damping) are marked with black colour and the results obtained for the shock absorber in the nominal technical condition are marked in blue. The results presented are obtained while driving at a constant speed of $70 \mathrm{~km} / \mathrm{h}$. The vehicle moved on a good surface.

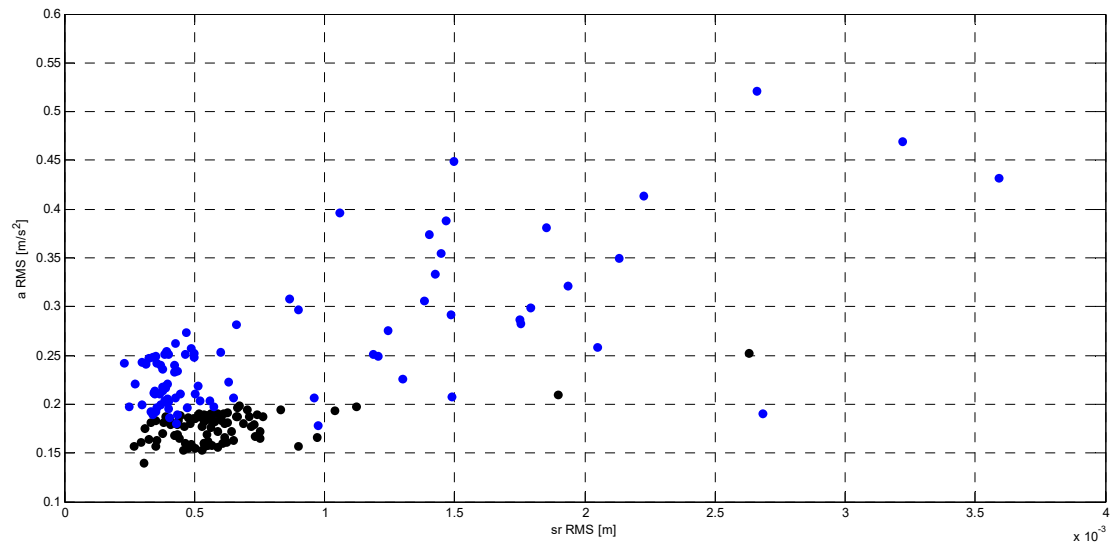

Fig. 6. Test results on the real object. Black - worn shock absorber, blue - efficient shock absorber

\section{Conclusions}

The proposed method allows to evaluate the method of transferring vibration energy in the suspension system of a commercial vehicle depending on the damping characteristics. The change in damping affects the position of the point described by the coordinates in the form of effective values of accelerations of body vibrations and relative displacements of the wheel and body. Using the proposed method, the technical condition of the commercial vehicle suspension can be assessed in terms of vibration damping for any type of extortion.

\section{References}

[1] Warczek J. A study on exposing the driver of a commercial vehicle to mechanical vibration. Scientific Journal of Silesian University of Technology, Series Transportation, Vol. 94, 2017, p. 229-238.

[2] Warczek J., Burdzik R., Peruń G. The method for identification of damping coefficient of the trucks suspension. 5th International Congress of Technical Diagnostics, Krakow, Poland, 2012, p. 281-289.

[3] Konieczny L., Warczek J., Młyńczak J., Zawisza M. Free vibration method for technical condition assessment of automotive shock absorbers. Diagnostics, Vol. 18, Issue 3, 2017, p. 47-53.

[4] Crawford S. F. Waves. Berkeley Physics Course. Vol. 3. McGraw-Hill Book Company, New York, 1968. 